\title{
Quality in practice
}

\section{Achieving quality in hospital practice}

\author{
Fiona Moss
}

The concern of individual practitioners for the care given to individual patients is a vital component of good clinical practice. But, as Robert Maxwell observed, "an honest concern about quality, however genuine, is not the same as methodical assessment based on reliable evidence." And as individual concern unaccompanied by systematic analysis is not a measure of any aspect of the quality of care, it neither guarantees a particular standard of practice nor is it a proxy for quality assurance.

\section{What is the problem?}

There is no shortage of evidence to support the argument for the introduction of quality assurance into clinical practice. Many published studies, which have assessed the quality of care with measurable criteria, have shown wide gaps between actual care and accepted good practice. For example, in a large proportion of deaths from asthma there is evidence of lack of appropriate medication or referral or physiological measurement ${ }^{23}$; similar findings were reported in studies of routine care given to patients admitted to hospital with acute severe asthma. ${ }^{4-6}$ Underuse of $\beta$ blockers and aspirin for patients who have had myocardial infarction ${ }^{7}$ and of streptokinase for those admitted with myocardial infarction ${ }^{89}$ has been described. Variation in use of procedures and demonstration of inappropriate use of invasive investigations such as coronary angiography ${ }^{10}$ and of prescribed drugs such as antibiotics ${ }^{11}$ indicate a degree of uncertainty in clinical decision making - a factor which may at least partly explain some of the differences between actual and accepted practice.

Quality assurance and medical audit are processes which seek to improve the quality of care by addressing differences between accepted good care and actual practice. To make sense of such an approach the analysis clearly has to be systematic and unbiased.

Medical audit: leap in the dark?

Theories of medical audit and quality assurance have often been discussed in the medical literature during the past decade. ${ }^{12-14}$ In practice, in the 1980 s only a few pioneer units included medical audit in their routine pattern of work. But in 1990 medical audit was introduced to all doctors as part of the package of reforms in the government white
Sources of difficulty in assessing quality of routine clinical care

- Interprofessional ("tribal") boundaries

- Little available information about routine practice

- Concepts of quality are poorly understood

- Natural suspicion about comparisons

- Change is difficult and creates uncertainty

- Measures of outcome and effectiveness are lacking

- Patients' views have never predominated

paper Working for Patients ${ }^{15}$ and imposed under the direction of the subsequent Department of Health circulars. ${ }^{16} 17$

Introducing a system for methodical assessment of clinical care into routine practice is a huge undertaking, with many potential sources of difficulty (box). The deficits and defects which exist in clinical care and its support systems have first to be acknowledged before their causes can be unravelled. Buying into quality assessment and quality assurance as part of clinical practice will include confronting firmly held assumptions about what we do.

Implicit in the concept of medical audit is that change is required for improvement in care. Promoting change is a complex process, which creates uncertainty and can be difficult to manage. But audit without a commitment to change is unlikely to have any effect on clinical practice. ${ }^{18}$

Some have responded to the institution of medical audit with scepticism. After all, if audit is such a good thing why was it imposed through Department of Health circulars and not allowed to percolate naturally through the system as if it were a new piece of imaging equipment? This scepticism is not entirely unfounded. Audit is a relatively untested tool and is in many respects in the early stages of development. But it seems to have skipped from phase 2 to phase 4 of a development plan. Little thought has been given to marketing, and no mechanism has been developed for postmarketing surveillance. Uncertainty about its function, about what it is, about how to do it, and about who owns the audit process linger on.

The imposition of audit has faced doctors with a choice: between paying lip service and griping about audit - turning up to meetings
Authority, Londo W2 3QR

Fiona Moss, editor 
just enough to count and little else - or, through facing up to the problems of clinical practice and uncertainties associated with change, contributing to the development of a process which could have an important impact on the quality of care given to patients.

\section{What has medical audit to offer that is new?}

Medical audit offers a setting in which the quality of care can be measured against agreed standards and assessed in a structured and critical manner. Its potential lies in its development as an internal, reflective process centred on peer review rather than as an external, inspectorial process. Audit has been characterised as a rigorous clincial science with nine distinct steps. ${ }^{19}$ All quality assurance programmes, including medical audit, extend beyond regular audit or quality assurance meetings. Setting up an audit entails consideration of the aspects of care which contribute to quality; thinking through the appropriate questions to ask; setting standards; estimating the number of cases which need to be reviewed; and working out approaches to measurement and collection of data relevant to the audit. Finally, the data have to be analysed appropriately, and performance has to be compared with agreed standards. Beneficial change is stimulated by sharing this information and discussing its implications with the whole clinical team.

The stated objective of medical audit is to improve care - and quite simply to give patients a better deal from the services provided. This and the emphasis on a methodical, systematic, and critical analysis of those aspects of care which contribute to quality distinguish audit from the rest of the hierarchy of clinical meetings: case presentations at staff rounds, clinicopathological conferences, and morbidity and mortality meetings. Each may have some relevance to the quality of care, but none is a substitute for medical audit.

\section{Medical audit: the challenge}

Medical audit is most likely to promote change in clinical practice when measurable criteria of the quality of care exist; standards of care have been agreed; there is access to information on a properly selected series of patients; and the clinical team can freely discuss the implications of the results of an audit and has the flexibility to be able to change practice to improve care. In practice, the conditions for many audits are less than satisfactory.

Much of clinical practice is not based on reliable scientific evidence, and agreed criteria for good care are not often available. Information about many aspects of patient care is recorded haphazardly and is difficult to retrieve. Medical notes, the source of much information for audit, are poorly kept, and even when audit focuses on the quality of notekeeping standards of clerking are difficult to maintain. ${ }^{20}$ Despite this gap between the theory and the real practical difficulties of auditing care many units, helped by extra money "ring fenced" for audit, have developed useful and responsive medical audit programmes.

The establishment of medical audit as a feature of clinical practice is being promoted through other initiatives. Measures of the quality of care are included in contracts for health care provision and, unless price becomes an overriding issue, this should guarantee that the quality of care is an essential aspect in both the commissioning and the delivery of health care. Audit of provider units will be central to the process of assuring the quality of care that is set out in contracts and will be an important marker for providers and purchasers. Bilateral discussion between purchasers and providers is a potential forum for formulation of appropriate quality measures which are both achievable and also push providers towards continual improvement in care.

Further opportunity for progress in medical audit is provided through research into the evaluation of the outcomes from health care in terms which relate to patients' experience. Overviews which assess and weight the evidence for the effectiveness of clinical interventions for specific conditions are also contributing to the foundations of the audit process.

Increasing consumer concern about the quality of care received and about the availability of choices in health care, if it is recognised and understood, has the potential to accelerate the development of audit. Informed patient choice should guide clinical decision making and be the basis of quality improvement initiatives. One of the real challenges facing health care is to listen properly to consumers' views and allow consumers to influence the procurement of good quality care - but this challenge is yet to be addressed.

Paying for audit: what is the currency? Money has been allocated from central funds specifically for setting up medical audit. Inevitably, the return on the money invested is being questioned. The return, or effectiveness, of audit is improvement in patient care, and there is no single litmus test for this. But published reports of audits which "close the loop" and the annual audit reports now produced by all units indicate that the investment is a sound one.

Investment in medical audit includes much more than just money and it is a long term venture. Short term returns are improbable; very high long term returns are likely, but pulling out early will incur considerable losses. Clinical practitioners must continue to monitor the effects of audit and to disseminate the results - so that experience in audit development can be shared and the results of audit (return on investment) shown.

Medical and clinical audit are currently funded separately and inequitably. Integration of medical and clinical audit will be more likely if funding is more equitable. Audit is a worthwhile investment which could have a 
considerable impact on the quality of patient care; it would be wise to keep up the payments.

\section{Medical audit: the future}

The institution of medical audit has committed the medical profession to the idea of quality assurance. But will medical audit continue to be the most appropriate approach for developing this aspect of clinical practice?

The purpose of any quality improvement initiative must be to make the health care system more responsive to patients' needs. To be effective such initiatives need to include the work of all those who contribute to care. Medical audit - which looks at only the work of doctors - does not approach the quality of care from a complete, and therefore patient focused, view.

Substantial and lasting improvements in patient care are unlikely if the work of different professional groups continues to be assessed separately. A reduction in mortality from gastrointestinal haemorrhage from $11 \%$ to $4 \%$ has been reported after the establishment of a specialist gastrointestinal ward. ${ }^{21}$ Surely, this could not have been achieved without physicians, surgeons, nurses, and managers working together to a common purpose? The effect of this team approach to care on patient outcome (assuming that 250 people with gastrointestinal haemorrhage are admitted annually) is 18 lives saved each year. Other effects of a coordinated approach to care include the benefits to both education and training.

Medical audit makes sense only if it becomes part of clinical audit, which involves the assessment of the work of the whole clincial team by all those who contribute to care (box). The focus of all quality assurance must be the resulting outcome and quality of life for patients and their experience of the whole process of health care.

\footnotetext{
1 Maxwell $R$. Quality assessment in health. $B M^{\gamma}$ 1984;288:1470-2

2 Omerod LP, Stapleforth DE. Asthma mortality in Birmingham. BMF 1980;280:687-90.
}

\section{Definition of clinical audit}

Clinical audit is the systematic critical analysis of the quality of clinical care, by all those who contribute to care. It includes the procedures used for diagnosis and treatment, the use of resources, and the resulting outcome and quality of life for the patient - for this patients' views must be sought. Its objectives are improvement in the quality of clinical practice

3 British Thoracic Association. Death from asthma in two regions of England. BMY 1982;294:1255-8.

4 Bucknall CE, Robertson C, Moran F, Stevenson RD. Differences in hospital asthma management. Lancet 988;i:748-50.

5 Bell D, Layton AJ, Gabbay J. Use of a guideline based questionnaire to audit hospital care of acute asthma. $B M \mathcal{F}$ 1991;302:1440-3.

6 Eason J, Markowe HLJ. Controlled investigation of deaths in the North East Thames region. BMJ 1987;294:1255-8.

7 Eccles M, Bradshaw C. Use of secondary prophlyaxis against myocardial infarction in the north of England. BMF 1991;302:91-2.

8 Hendra TJ, Marshall AJ. Increased prescription of thrombolytic treatment to elderly patients with suspected acute myocardial infarction associated with audit. $B M \mathcal{F}$ 1992;304:423-5.

9 Burrell C, Skehen JD, Cowley ML, Barrett CW, Mills PG. District use of thrombolytic agents. BMF 1990; 300:237-8.

10 Gray D, Hampton JR, Bernstein SJ, Kosekoff J, Brook RH. Audit of coronary angiography and bypass surgery Lancet 1991;335:1317-20.

11 Moss FM, McNicol MW, McSwiggan DA, Miller DL Survey of antibiotic prescribing in a district hospital. II. Lower respiratory tract infection. Lancet 1981;ii:407-9.

12 Shaw CD. Aspects of audit. 1. The background. $B M$ 1980;280:1256-8.

13 Mitchell M, Fowkes FG. Audit reviewed: does feedback of performance change clinical behaviour? $f(R$ Coll Physicians Lond 1985;19:251-4.

14 Shaw CD, Costain DW. Guidelines for medical audit: seven principles. BMY 1989;299:498-9.

15 Department of Health Working for parients. London: HMSO, 1989. (Cmnd 555.)

16 Department of Health. Medical audit in the hospital and community health services. London: DoH, 1991 (HC(91)2.)

17 Department of Health. Medical audit in the family practitioner services. London: DoH, 1990. (FP(90)8.)

18 Stocking B. Promoting change in clinical practice. Quality in Health Care 1992;1:56-60.

19 Russell IT, Wilson BJ. Audit: the third clinical science? Quality in Health Care 1992;1:51-5.

20 Gabbay J, Layton AJ. Evaluation of audit of medical inpatient records in a district general hospital. Quality in Health Care 1992;1:43-7.

21 Holman RA, Davis M, Gough KR, Gartell P, Britton DC Smith RB. Value of a centralised approach in the management of haematemesis and melaena: experience in a district hospital Gut 1990;31:504-8. 